\title{
Treatment of Renovascular Hypertension Using Stent Implantation in an Elderly Patient with NIDDM
}

\author{
Mitsutaka Kitazawa, Hiroyasu Tamamura*, Shigeru NaKano, Toshikazu Kigoshi and Kenzo Uchida
}

\begin{abstract}
A 70-year-old man with NIDDM was diagnosed as having renovascular hypertension ( $\mathrm{RVH})$, based on a stenosis of the ostial portion of the left renal artery with markedly elevated plasma renin activity (PRA) in both the left renal vein and the peripheral blood, and positive captopril tests. After percutaneous transluminal renal angioplasty (PTRA), his blood pressure (BP) and PRA normalized. However, since restenosis occurred three months later, stent therapy was applied, and consequently BP and PRA normalized immediately after this procedure. During the one-year follow-up, side effects have not been noted. We propose that stent therapy may be feasible for ostial renal artery stenosis in elderly diabetic patients.
\end{abstract}

(Internal Medicine 39: 464-467, 2000)

Key words: PTRA, Atherosclerosis

\section{Introduction}

Renovascular hypertension (RVH) is one of the etiologies of secondary hypertension, and is found in about $1 \%$ of the entire hypertensive population (1-3). In such cases, a surgical procedure has generally been performed. In 1978, Grüntzig et al (4) first introduced percutaneous transluminal renal angioplasty (PTRA) for RVH due to renal arterial stenosis. This technique has been used widely because of its effectiveness, safety and low cost as compared with surgical revasculizations $(5,6)$. However, it was recently pointed out that PTRA might be less effective in cases of RVH due to ostial stenosis of the renal artery because of the relatively high incidence of restenosis (6).

For editorial comment, see $\mathrm{p} 438$.

Angioplasty with balloon expansion and stent implantation, which was used for coronary arterial diseases (7), was first applied for RVH in 1991 (8). Since then, angioplasty with stent implantation has been considered to be more successful than PTRA alone and decreased postoperative restenosis (9-11). With regard to the effectiveness of stent implantation on RVH, there are only a few reports in Japan (12-16), while many studies have been conducted in other countries (9-11).

We report here on an aged patient with diabetes mellitus in whom restenosis occurred three months after PTRA for RVH due to left renal arterial stenosis, and subsequent angioplasty with stent implantation was performed successfully.

\section{Case Report}

A 70-year-old man was admitted to our hospital because of vertigo on February 11, 1998. He had been treated for hypertension and diabetes mellitus at a local clinic for the past 20 years. On admission, physical examination showed a height of $169 \mathrm{~cm}$, body weight of $65 \mathrm{~kg}$, and BP of $160 / 104 \mathrm{mmHg}$ with a regular pulse rate of 60 beats/min. Fundoscopy revealed hypertensive and sclerotic changes, and diabetic retinopathy classified as Scheie $\mathrm{H}_{0} \mathrm{~S}_{1}$ and Scott 0, respectively. His knee jerk was decreased. Abdominal bruit was not audible. The routine laboratory data were as follows: normal total cholesterol (180 $\mathrm{mg} / \mathrm{dl})$, low HDL-cholesterol (27 mg/dl), and high fasting blood glucose $(301 \mathrm{mg} / \mathrm{dl})$ and HbAlc $(9.0 \%)$. Coagulation parameters were within the normal ranges. The 24-hour urinary albumin excretion rate was $10.5 \mu \mathrm{g} / \mathrm{min}$. The glomerular filtration rate (GFR) was $67.7 \mathrm{ml} / \mathrm{min}$, indicating mild renal dysfunction. The remainder of the laboratory data were unremarkable.

Electrocardiogram was normal. Renogram showed slight deterioration in bilateral renal function (Fig. 1A). On abdominal computed tomography, no difference in kidney size was observed, but atherosclerotic changes in the abdominal aorta were present. The basal level of plasma renin activity (PRA) was elevated $(4.8 \mathrm{ng} / \mathrm{ml} / \mathrm{h})$, and markedly responded to 10.0 $\mathrm{ng} / \mathrm{ml} / \mathrm{h}$ during a furosemide test $(80 \mathrm{mg}$ furosemide plus 4hour upright posture). In a captopril test ( $25 \mathrm{mg}$ captopril per orally administrated), the PRA was elevated from 3.9 to 51.4 $\mathrm{ng} / \mathrm{ml} / \mathrm{h}$. In a renogram performed simultaneously during this

From the Division of Endocrinology, the Department of Internal Medicine, and *Radiology, Kanazawa Medical University, Ishikawa

Received for publication June 24, 1999; Accepted for publication January 4, 1999

Reprint requests should be addressed to Dr. Shigeru Nakano, the Division of Endocrinology, Department of Internal Medicine, Kanazawa Medical University, 1-1 Daigaku, Uchinada, Ishikawa 920-0293 

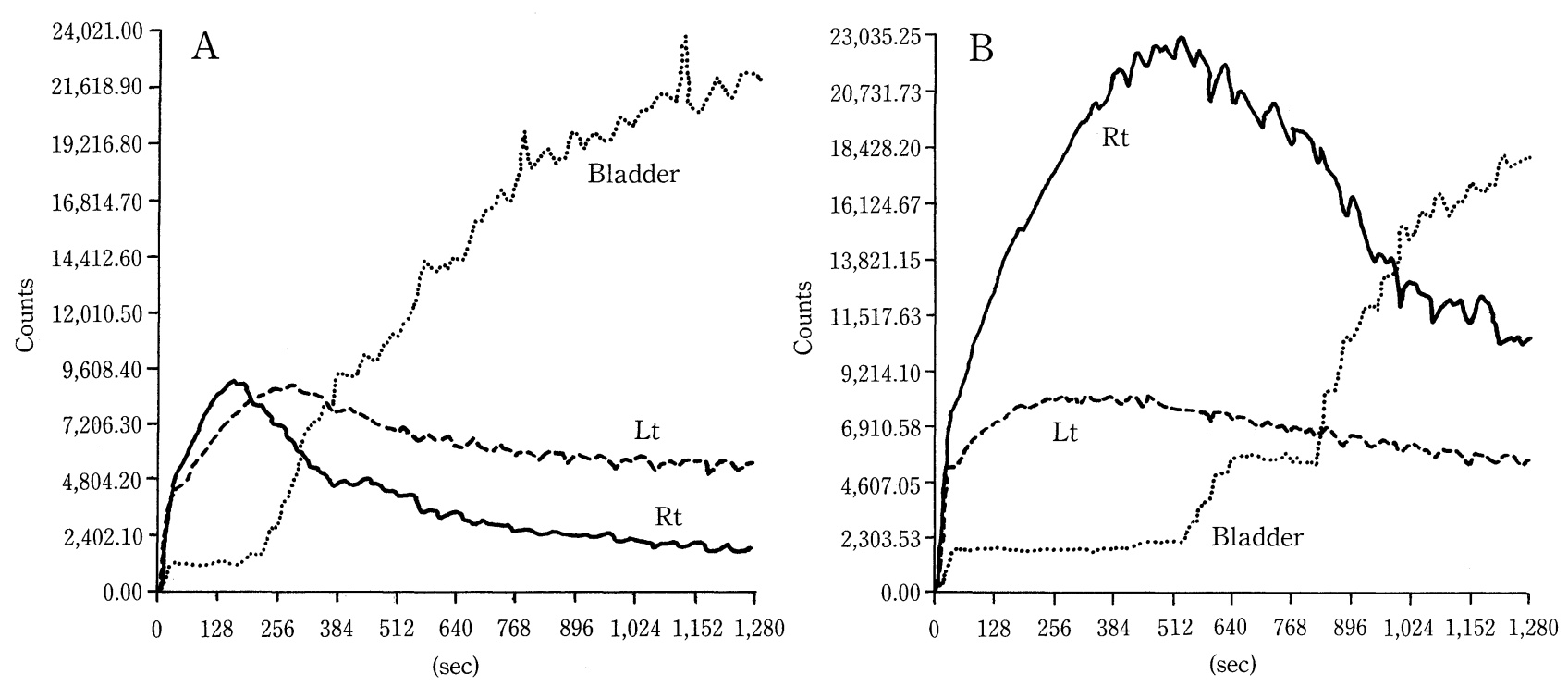

Figure 1. A) ${ }^{99 m}$ Tc-DTPA renogram showing bilateral mild renal dysfunction. However, no laterality of renal function was detected. B) ${ }^{99 m}$ Tc-DTPA renogram after $25 \mathrm{mg}$ captopril per orally administrated, showing a marked decrease in function of the left side kidney.

test, the difference in the bilateral renal blood flow became marked (17), and depression in the left renal function was revealed (Fig. 1B). Renal angiography showed approximately $80 \%$ ostial stenosis in the left renal artery (Fig. 2). Selective renal venous sampling revealed a marked elevation in PRA obtained from the left renal vein $(2.9 \mathrm{ng} / \mathrm{ml} / \mathrm{h})$ as compared with the right side $(1.1 \mathrm{ng} / \mathrm{ml} / \mathrm{h})$ : the left to right ratio was 2.6 , suggesting renin release from the left kidney. Thus, we diagnosed RVH due to the left renal artery stenosis.

PTRA was performed on May 6, 1998, resulting in improvement of the previously stenotic lesion of the left renal artery. Within 30 minutes of PTRA, BP level normalized to 120/72 $\mathrm{mmHg}$. He was maintained without any anti-hypertensive drugs and discharged in 10 days. On August 14, three months after angioplasty, he was readmitted because of vertigo and headache with an increase in BP to $168 / 100 \mathrm{mmHg}$ accompaning the elevated PRA $(5.9 \mathrm{ng} / \mathrm{ml} / \mathrm{h})$. Angiography revealed restenosis in the same region, showing a diameter of $1.0 \mathrm{~mm}$ and length of $7.3 \mathrm{~mm}$, which was $0.5 \mathrm{~mm}$ distance from the origin of the aortic trunk. For the treatment of this restenosis lesion, we selected PTRA with stent implantation. One Palmaz vascular stent (Johnson and Johnson Co, Warren, NJ, USA) was implanted in the ostial region of the main artery and the other in a branched artery in which mild stenosis continuing from main artery was recognized (Fig. 3). After the procedure, the patient was administered $300 \mathrm{mg}$ of ticlopidine, an anticoagulant drug. One year after the therapy, he still has normal PRA and normal BP without any antihypertensive drugs.

\section{Discussion}

The present case of RVH showed a stenosis of $80 \%$ at the

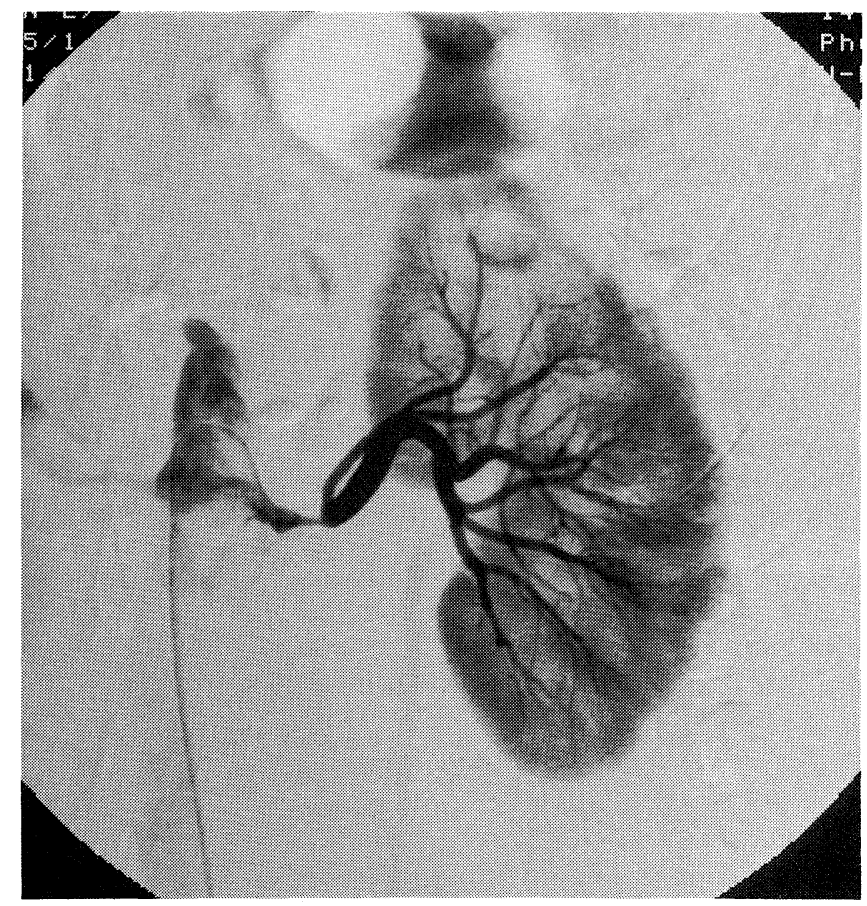

Figure 2. Angiogram shows the stenosis in the left renal artery. PTRA was performed on this lesion.

ostial region of the left renal artery on aortogram, the PRA level at the left renal vein was 2.6-fold higher than at the right one, and there were positive findings in PRA and renogram with captopril loading. In particular, renogram with captopril 
was effective for the diagnosis of $\mathrm{RVH}$, and the underlying mechanism was thought to be as follows: the GFR of an affected kidney is dependent on the effects of angiotensin II on the efferent glomerular arterioles, so that inhibition of angiotensin converting enzyme produces a marked decrease in GFR. However, the changes in renal blood flow at the other side are less pronounced. Therefore, the characteristic effect of captopril in a kidney with a renal artery stenosis causes a decreased DTPA uptake (17) as observed in Fig. 1B.

Although we initially considered surgical revascularization in the present case, as previous reports $(1,5-7)$, PTRA was first chosen due to less invasiveness. After the PTRA, the stenotic region was expanded, and hyperreninemia as well as hypertension improved promptly. However, three months later,

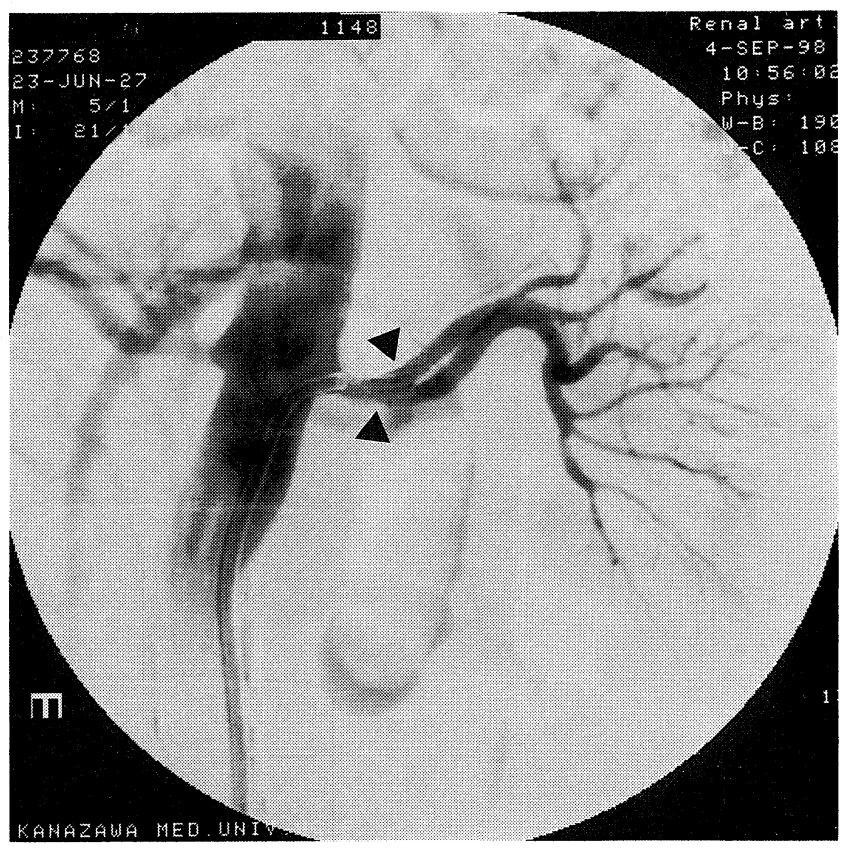

Figure 3. Angiogram of the left renal artery. The arrowheads indicate the implanted stents for the restenotic lesions. the PRA increased again and hypertension recurred with restenosis in the same region on angiograms. Therefore, we performed angioplasty with a stent implantation. Those abnormal findings improved rapidly, and the PRA and BP has remained within the normal range to date, one year after PTRA with stent implantations. Thus, this treatment was considered to have been successful in our case.

In cases with marked stenosis and an increase in renin release from the affected kidney, the risk of vascular complications or renal dysfunction is high, and PTRA has been thus performed (18). Since the first application of PTRA for the treatment of RVH in 1978 (4), PTRA, which is simpler, safer, and less expensive than surgical revascularization, has been used widely for the last 20 years. However, in patients who underwent PTRA for renal arterial stenosis caused by atherosclerosis, a high incidence of fatal complications such as cholesterol thrombosis $(19,20)$, rupture of the renal artery, renal arterial thrombosis, segmented renal infarction, hematoma, and myocardial infarction (19), have been reported as adverse events. Furthermore, a high rate of restenosis (35-65\%) within about six months to one year after PTRA was reported (19, 21). Thus, although PTRA is safer than surgical procedure, stenosis recurs at a higher rate and its long-term effectiveness has been questioned $(19,21)$. Recently, various types of stents, including Palmaz stents, have been used widely for angioplasty in coronary arterial diseases (7). However, for angioplasty in RVH only a few studies (12-16) (Table 1) have been reported in Japan. Various reasons are conceivable for this situation. First, the medical insurance has only covered a stent implantation therapy for RVH since 1997. Secondly, with regard to racial difference Japanese have less degree of hyperinsulinemia and hyperlipidemia compared with American (22). In fact, the frequencies of various vascular events differ among races (23). Finally, stent therapy requires special skill. Since Palmaz stents were first implanted for patients with RVH in 1991 (8), prognostic data have been reported: i.e. the incidence of restenosis was about $16 \%(9,10,24)$, which was less than that in PTRA alone. As compared with surgical treatment, the treatment with stent was demonstrated to be technically less risky and to be equivalent in protection of renal blood flow and reduction in BP. Moreover, in a non-discriminative comparison study (25)

Table 1. Summary of Reported Japanese Cases of Stent Implantation Therapy for Renovascular Hypertension

\begin{tabular}{|c|c|c|c|c|c|c|c|c|}
\hline Authors & Year & Age/Gender & $\begin{array}{l}\text { Blood Pressure } \\
(\mathrm{mmHg})\end{array}$ & $\begin{array}{c}\text { Location } \\
\text { (Renal artery) }\end{array}$ & Etiology & Stent & $\begin{array}{l}\text { Underlying } \\
\text { disease }\end{array}$ & Outcome \\
\hline Hata $M$ et al (12) & 1997 & 57/Female & $180 /-$ & right & $\begin{array}{l}\text { dissection of aorta } \\
\text { (Stanford A type) }\end{array}$ & Palmaz stent & hypertension & successful \\
\hline Hata $M$ et al (13) & 1997 & 56/Male & $180 /-$ & right & $\begin{array}{l}\text { dissection of aorta } \\
\text { (Stanford B type) }\end{array}$ & $\begin{array}{c}\text { Scneider } \\
\text { Wall stent }\end{array}$ & hypertension & successful \\
\hline Izumiya $\mathrm{M}$ et al (15) & 1998 & 80/Male & $240 / 90$ & bilateral & atherosclerosis & Palmaz stent & hypertension & successful \\
\hline Tagami R et al (16) & 1998 & 44/Male & $220 / 118$ & left & unknown & Palmaz stent & none & successful \\
\hline
\end{tabular}




\section{Stent Implantation for RVH}

on PTRA and treatment with stents limited to ostial atherosclerotic renovascular lesions, the PTRA with stents showed a significantly lower incidence of restenosis even in long-term observation than PTRA alone (25), suggesting that the treatment with stent is the first choice for initial angioplasty (25).

In the present case, we conducted anti-coagulant therapy with the some protocol used after treatment with stents for ischemic cardiac disease (26). However, it has not yet been established what type of anti-coagulant therapy is needed as a countermeasure against restenosis after treatment with stents in the renal artery. Moreover, it is necessary to define the further roles of treatment with stents, taking into consideration of the Japanese characteristics of lesions and the risk factors of individual patients such as advanced age or diabetes mellitus. In addition, multi-institutional analysis in Japan will be necessary to evaluate the role of stent implantation for RVH.

\section{References}

1) Kaplan NM. Renal vascular hypertension. in: Clinical Hypertension. 7th ed, Lieberman E, Neal WW, Eds. Baltimore, Williams \& Wilkins, 1998: 301-321.

2) Horvath JS, Waugh RC, Tiller DJ, Duggin GG. The detection of renovascular hypertension: a study of 490 patients by renal angiography. Q J Med 51: 139-146, 1982.

3) Bijlstra PJ, Postma CT, de Boo T, Thien T. Clinical and biochemical criteria in the detection of renal artery stenosis. J Hypertens 14: 1033-1040, 1996.

4) Grüntzig A, Kuhlmann U, Vetter W, Lütolf U, Meier B, Siegenthaler W. Treatment of renovascular hypertension with percutaneous transluminal dilatation of a renal-artery stenosis. Lancet 1: 801-802, 1978.

5) Sos TA, Pickering TG, Sniderman K, et al. Percutaneous transluminal renal angioplasty in renovascular hypertension due to atheroma or fibromuscular dysplasia. N Engl J Med 309: 274-279, 1983.

6) Rimmer JM, Gennari FJ. Atherosclerotic renovascular disease and progressive renal failure. Ann Inter Med 118: 712-719, 1993.

7) Sigwart U, Puel J, Mirkovitch V, Joffre F, Kappenberger L. Intravascular stents to prevent occlusion and restenosis after transluminal angioplasty. N Engl J Med 316: 701-706, 1987.

8) Kuhn FP, Kutkuhn B, Torsello G, Modder U. Renal artery stenosis: preliminary results of treatment with the Strecker stent. Radiology 180: 367437, 1991.

9) van de Ven PJ, Beutler JJ, Kaatee R, et al. Transluminal vascular stent for ostial atherosclerotic renal artery stenosis. Lancet 346: 672-674, 1995.

10) Blum U, Krumme B, Flugel P, et al. Treatment of ostial renal-artery stenoses with vascular endoprostheses after unsuccessful balloon angioplasty. N Engl J Med 336: 459-465, 1997.
11) Dorros G, Jaff M, Mathiak L, et al. Four-year follow-up of Palmaz-Schatz stent revascularization as treatment for atherosclerotic renal artery stenosis. Circulation 98: 642-647, 1998.

12) Hata M, Zuguchi M, Saito H, Tabayashi K. Stent angioplasty for renovascular disease associated with acute aortic dissection. Ann Thorac Surg 63: 244-246, 1997.

13) Hata M, Yamaya $K$, Sadahiro M, et al. A Case Report: Successful treatment of acute type B aortic dissection with renal and leg ischemia. Kyoubugeka 50: 763-766, 1997.

14) Miyajima A, Sumitomo M, Hayakawa M, Nakamura H, Kaji T. Transluminal vascular stent implantation for a patient with renovascular hypertension due to renal artery stenosis. Clin Exp Nephrol 2: 72-74, 1998.

15) Izumiya $M$, Ise $T$, Takakuwa $H$, et al. A Case of bilateral renovascular hypertension whose renal function improved after unilateral stent therapy (in Japanese). Jpn J Nephrol 40: 422, 1998.

16) Tagami R, Yamanaka M, Tada R, Yasuda H, Mori Y, Sui O. Treatment of renovascular hypertension using stent implantation. A case report (in Japanese). Nishinihon J Urol 60: 153, 1998.

17) Wenting GJ, Tan-Tjiong HL, Derkx FH, de Bruyn JH, Man in't Veld AJ, Schalekamp MA. Split renal function after captopril in unilateral renal artery stenosis. Br Med J 288: 886-890, 1984.

18) Working Group on Renovascular Hypertension. Detection, evaluation, and treatment of renovascular hypertension. Final report. Arch Intern Med 147: 820-829, 1987.

19) Ramsay LE, Waller PC. Blood pressure response to percutaneous transluminal angioplasty for renovascular hypertension: an overview of published series. Br Med J 300: 569-572, 1990.

20) Mahler F, Triller J, Weidmann P, Nachbur B. Complications in percutaneous transluminal dilatation of renal arteries. Nephron 44 Suppl 1: 6063, 1986.

21) Plouin PF, Darne B, Chatellier G, et al. Restenosis after a first percutaneous transluminal renal angioplasty. Hypertension 21: 89-96, 1993.

22) Imazu $M$, Sumida $K$, Yamabe $T$, et al. A comparison of the prevalence and risk factors of high blood pressure among Japanese living in Japan, Hawaii, and Los Angeles. Public Health Rep 111 Suppl 2: 59-61, 1996.

23) Stemmermann GN, Hayashi T. Atherosclerosis in Japanese in Japan and in Hawaii: a summary review of pathology studies in Honolulu and Hiroshima. Hawaii Med J 49: 262-264, 1990.

24) Tullis MJ, Zierler RE, Glickerman DJ, Bergelin RO, Cantwell-Gab K, Strandness DE Jr. Results of percutaneous transluminal angioplasty for atherosclerotic renal artery stenosis: a follow-up study with duplex ultrasonography. J Vasc Surg 25: 46-54, 1997.

25) van de Ven PJ, Kaatee R, Beutler JJ, et al. Arterial stenting and balloon angioplasty in ostial atherosclerotic renovascular disease: a randomised trial. Lancet 353 (9149): 282-286, 1999.

26) The EPISTENT Investigators. Randomised placebo-controlled and balloon-angioplasty-controlled trial to assess safety of coronary stenting with use of platelet glycoprotein-IIb/IIIa blockade. Lancet 352 (9122): 87-92, 1998 